\title{
A blood pressure clinic in a health centre
}

\author{
D. G. BEEVERS* \\ M.B., M.R.C.P. \\ SHEENA DunCan $\dagger$ \\ R.G.N. \\ C. S. NeLSON $\ddagger$ \\ M.B., M.R.C.P. \\ P. L. PADFIelD* \\ M.B., M.R.C.P. \\ * MRC Blood Pressure Unit, Western Infirmary, Glasgow G11 6NT, † Department of Community \\ Medicine, University of Glasgow, and $\ddagger$ Royal Alexandra Infirmary, Paisley
}

\begin{abstract}
Summary
Following a screening survey for hypertension in Renfrew, a blood pressure clinic was established in a health centre. Three hospital doctors, each working an average of two sessions weekly, saw 368 patients. A specially trained nurse played an important part in the running of the clinic. Attendance of patients was high, and defaulting amongst those needing treatment was low. Blood pressures were well controlled in $75 \%$ of the patients. The clinic has proved an acceptable method of managing large numbers of hypertensives without reference to hospital.
\end{abstract}

\section{Introduction}

Screening surveys have demonstrated that mild hypertension is common and, in a large proportion of cases, previously undiagnosed (Lew, 1973; Prineas, Stephens and Lovell, 1973; Wilber and Barrow, 1972; Hawthorne, Greaves and Beevers, 1974; Langfield, 1973).

Should trials in progress in this country and abroad confirm that therapy is of benefit (Peart, 1973; Abernethy, 1974; Miall and Brennan, 1976; Wilhelmsen, 1975), there would be a large increase in the number of patients requiring treatment. It is unlikely and possibly undesirable that hospitals should deal with the extra work load, and the testing of alternative and simpler forms of management is necessary.

This paper describes the establishment and organization of a blood pressure clinic, staffed by hospital physicians but situated in a general practitioner health centre. The data are based on experience during $2 \frac{1}{2}$ years on the frequency and severity of hypertension, and its response to withholding, instigating, withdrawing and continuing treatment. Other reports give results of special investigations and studies performed (Beevers et al., 1974a, b; Padfield et al., 1975).

Correspondence: MRC Blood Pressure Unit, Western Infirmary, Glasgow G11 6NT.
The blood pressure clinic

Medical care for the Burgh of Renfrew (population 19,000 ) is provided by nine family doctors operating from a recently opened health centre. A branch of the Glasgow Blood Pressure Clinic (1972) was set up in the health centre with the co-operation of the family doctors, the Medical Officer of Health and the Glasgow M.M.R. Cardiorespiratory Screening Unit (Hawthorne, Gillis and MacLean, 1972).

The clinic uses two consulting rooms and a waiting and documentation area. Direct access is available to the general practitioners and their records. Special equipment at the clinic includes a refrigerator, a tape recorder, a microscope, an electrocardiograph and a small centrifuge for the separation of samples of serum for electrolyte estimations. Blood pressures are measured using the London School of Hygiene Sphygmomanometer (Rose, Holland and Crowley, 1964). The clinic is staffed by three hospital registrars each working an average of two sessions weekly during mornings, afternoons or evenings.

Blood pressures are taken by a nurse who has been trained to use the special sphygmomanometer. She also acts as secretary and receptionist. Other secretarial, radiological and laboratory help is provided at the Western Infirmary, Glasgow.

Initial patient interviews, including a full clinical examination, last $45 \mathrm{~min}$. Details of previous blood pressures are extracted from the family doctors' records. Data are recorded on the Glasgow Blood Pressure Clinic document (1972). Follow-up visits lasting $15 \mathrm{~min}$ are arranged and patients are encouraged to attend at other times should they so wish. Defaulters are usually sent new appointments.

\section{Patients}

Three hundred and ninety-four subjects between the ages of 45 and 64, found to have a diastolic blood pressure greater than $95 \mathrm{mmHg}$ on two occasions at the screening survey (Hawthorne, Greaves and Beevers, 1974), form the main source of 


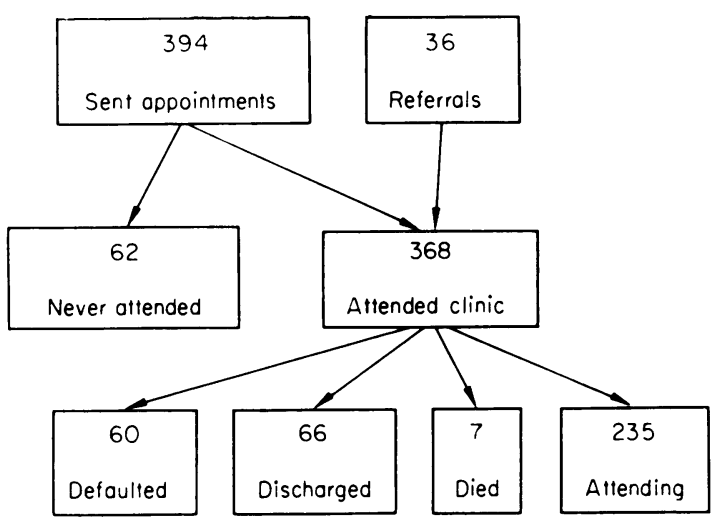

FIG. 1. Source and attendance of 430 subjects at clinic.

patients for the clinic (Fig. 1). A further thirty-six patients, not eligible for screening, were referred directly by general practitioners or from surrounding hospitals. Of those sent appointments, all but sixtytwo $(14.4 \%)$ attended; six of these did not attend because they were already receiving antihypertensive therapy from their general practitioner. In the $2 \frac{1}{2}$ years since the clinic was opened, sixty subjects $(16.2 \%)$ have defaulted. Most of these were being seen 6-monthly and were untreated because their blood pressure had fallen to low levels.

During the latter part of this period, the clinic's capacity to accept new patients has increased and a more flexible appointment system has been arranged, enabling patients to attend for extra visits at any time during clinic hours, and be included with only a short period of waiting.

\section{Blood pressure and its control}

All of the 368 subjects who have attended the clinic had a diastolic pressure of $95 \mathrm{mmHg}$ or more on two occasions. Of these, 212 have been followed for 12 months or more (Figs 2 and 3). For various reasons treatment was not started in ninety patients in whom blood pressures tended to fall slightly (Group 1). Treatment was started in forty-one previously untreated patients (Group 2) and blood pressures fell more markedly, but levels were higher initially in this group than in Group 1, and it cannot be concluded that treatment was the sole explanation for the drop in pressure.

Treatment was continued, intensified or changed in sixty-one patients (Group 3), generally with improved control, although after 1 year there remained twenty-four of 102 treated patients (Groups 2 and 3 together) with diastolic pressures of $100 \mathrm{mmHg}$ or more.

Antihypertensive therapy was usually withheld when the patient was first seen so that blood pressure

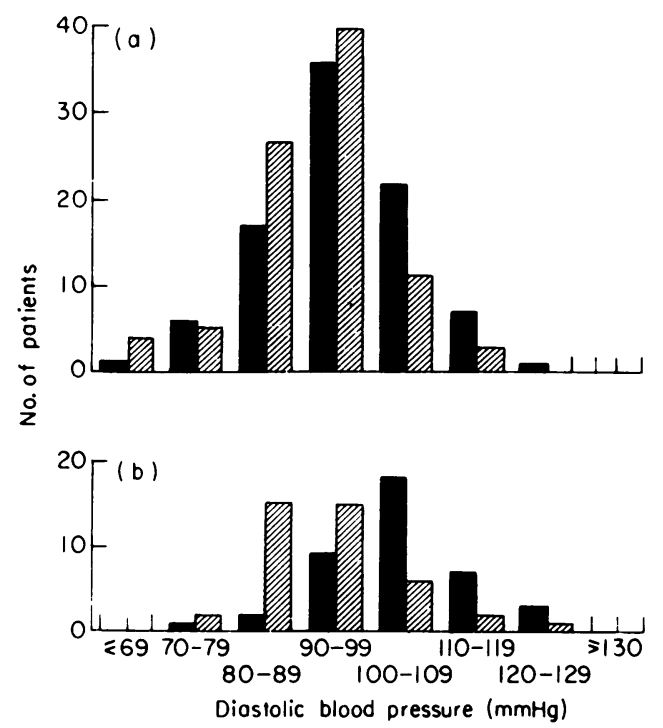

Fig. 2. Change in blood pressure in 131 receiving no treatment at first attendance. (a) Group 1, ninety patients. Untreated initially; mean DBP $94.8 \mathrm{mmHg}$ \pm 10.5 s.d. Remained untreated; mean DBP 90.2 $\mathrm{mmHg} \pm 10.5$ s.d. Paired $t=3.64 ; P<0.001$. (b) Group 2, forty-one patients. Untreated initially; mean DBP $103.4 \mathrm{mmHg} \pm 11.0$ s.d. Treatment started; mean DBP $92.9 \mathrm{mmHg} \pm 10.3$ s.d. Paired $t=5.44$; $P<0.001$. $\square$, First visit; $\mathbb{Z}$, after 1 year.
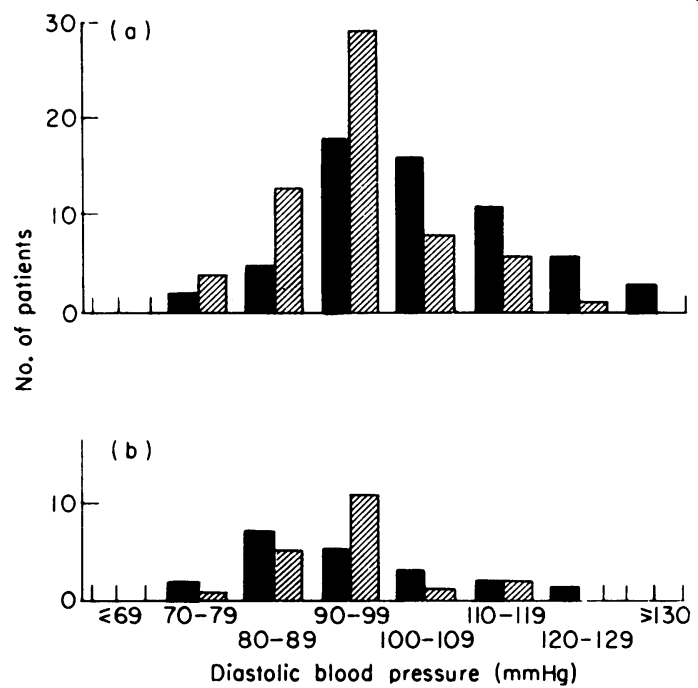

Fig. 3. Change in blood pressure in eighty-one patients receiving treatment at first visit. (a) Group 3, sixty-one patients. On treatment initially; mean DBP 104.1 $\mathrm{mmHg} \pm 13.9$ s.d. Remained treated; mean DBP 94.9 $\mathrm{mmHg} \pm 10.8$ s.d. Paired $t=5.15 ; P<0.001$. (b) Group 4, twenty patients. On treatment initially; mean DBP $93.4 \mathrm{mmHg} \pm 13.8$ s.d. Treatment stopped; mean DBP $92.9 \mathrm{mmHg} \pm 8.9$ s.d. Paired $t=0.23$, not significant. $\square$, First visit; $\mathbb{Z}$, after 1 year. 
could be assessed and reliable measurements made of electrolytes, renin and aldosterone in the untreated state. Treatment was not restarted in twenty patients (Group 4) and after 1 year's follow-up diastolic blood pressure had risen to $100 \mathrm{mmHg}$ or more in only three. All patients in this group had hypertension (as defined earlier) at the screening survey and were hypertensive when seen and subsequently treated by the general practitioner; none had evidence of myocardial infarction on a routine electrocardiogram.

The choice of antihypertensive drugs used in the clinic is shown in Table 1. Regimes including diuretics were frequently used, but in many cases $\beta$-adrenergic receptor-blockers were used. An analysis of the drugs that were used in 1972 by the general practitioners before screening showed a different pattern, $\beta$-blockers rarely being used, and methyldopa and Rauwolfia derivatives used more often.

TABLE 1. The use of antihypertensive drugs (alone or in combination) in the Blood Pressure Clinic, compared with those used in 1972 by the General Practitioners

\begin{tabular}{lcc}
\hline $\begin{array}{c}\text { Drug (alone or in } \\
\text { combination) }\end{array}$ & $\begin{array}{c}\text { Clinic } \\
(\%)\end{array}$ & $\begin{array}{c}\text { General } \\
\text { practice } \\
(\%)\end{array}$ \\
\hline Tniazide diuretic & 61 & 48 \\
Methyldopa & 28 & 55 \\
B-blocker & 33 & 2 \\
Rauwolfia derivative & 0 & 15 \\
Adrenergic blocker & 8 & 1 \\
Non-thiazide diuretics & 1 & 5 \\
\hline
\end{tabular}

Of the 368 patients seen in the clinic, only eleven have needed referral to hospital for further investigation of their hypertension-five for suspected renal or renal artery disease, one for investigation of hypokalaemia and five on account of very severe or resistant hypertension.

\section{Discussion}

The ability of population surveys to detect patients with hypertension is undoubted, but their value is disputed (Sackett, 1974; Hawthorne, 1975; Turner and Ball, 1975). The issue can only be resolved when it is known if treating mild hypertension is worthwhile, since most cases detected are mildly hypertensive (Wilber and Barrow, 1972; Hawthorne, Greaves and Beevers, 1974). Projects in progress should provide this information (Miall and Brennan, 1976; Abernethy, 1974; Wilhelmsen, 1975). If treatment is justified two changes will probably follow: some form of screening will be needed to detect new cases since a high proportion are unaware that their blood pressure is elevated; and management of hypertension will need simplification.
Screening may be carried out by special units (Hawthorne, Gillis and MacLean, 1974; Prineas, Stephens and Lovell, 1973) or by general practitioners (Hart, 1970; Sinclair, 1969). The latter may be preferable and is probably cheaper and patients can receive immediate attention. It may be necessary for general practitioners, possibly with the assistance of hospital physicians, to establish special blood pressure clinics employing a simplified method of management. Little equipment is necessary and management can be streamlined, particularly if specially trained nurses are used. Such 'nursepractitioners' (Lancet, 1974) are effective in other fields (Moore et al., 1973; Spitzer et al., 1974).

Local health centre clinics are more convenient for patients than a hospital out-patient department, especially if evening clinics are held. A lower defaulter rate and increased patient compliance may be achieved. It is notable that hospital-based clinics in local health centres have been employed in other fields, including diabetes mellitus (Malins and Stuart, 1971).

Some authors have been pessimistic about the 'compliance' of symptomless hypertensives given drug therapy (Finnerty, Mattie and Finnerty, 1973; Sackett et al., 1975). This has not been a problem in our clinic as the majority of patients have kept their appointments. Most of the defaulters had blood pressures which had fallen to low levels without treatment and strenuous efforts were made to recall them. Where severe hypertensives defaulted, liaison with the general practitioners has usually led to the patients' return. The taking of tablets was less easy to assess.

Blood pressures fell spontaneously without treatment in many patients. Continued follow-up is necessary to determine the eventual course and prognosis. Of interest also is the small group in whom therapy was discontinued, and blood pressures remained low. Therapy may not have been needed in the first place, or possibly the blood pressures may rise later, but it is possible that in some there had been a resetting of the blood pressures to lower levels (Veterans Administration, 1975).

Drug therapy, where given, was generally successful, although $23 \%$ of patients still had diastolic pressures of $100 \mathrm{mmHg}$ or more at the 1 year follow-up. This figure is, however, lower than that reported in hospital out-patient clinic practice (Beevers et al., 1973) where initial levels of blood pressure tend to be higher. Whilst there is evidence that diastolic pressures should be reduced to less than $90 \mathrm{mmHg}$, some reduction is clearly better than none (Taguchi and Freis, 1974).

This clinic has provided many opportunities for clinical research, particularly as normotensive subjects from the epidemiological survey have been 
happy to attend to act as control groups in certain investigations. Studies of hypertension in relation to the renin-angiotensin system have been reported elsewhere (Beevers et al., 1974a, b), and studies of blood levels of lead and cadmium are in progress. A clinical trial of the treatment of mild hypertension (Miall and Brennan, 1976) is being carried out in some patients and also, via the central Glasgow Blood Pressure Clinic (1972), computer data are available for other studies.

In conclusion, the health centre blood pressure clinic has proved acceptable to patients, hospital physicians and general practitioners. The simplified protocol has been tested and found effective in managing a large number of hypertensive patients detected by a screening programme.

\section{Acknowledgment}

We acknowledge the support of the General Practitioners of Renfrew, as well as the Renfrewshire King Edward Memorial Trust and Dr T. Y. Bennie, Community Physician.

\section{References}

Abernethy, J.D. (1974) The Australian nation blood pressure study. Medical Journal of Australia, 1, 821.

Beevers, D.G., Fairman, M.J., Hamilton, M. \& Harpur, J.E. (1973) The influence of antihypertensive treatment over the incidence of cerebral vascular disease. Postgraduate Medical Journal, 49, 905.

Beevers, D.G., Fraser, R., Greaves, D.A., Hawthorne, V.M., Morton, J.J., Nelson, C.S., Padfield, P.L. \& YounG, J. (1974a). Hypokalaemia, angiotensin II and aldosterone in an unselected population of hypertensives. European Journal of Clinical Investigation, 5, 355.

Beevers, D.G., Nelson, C.S., Padfield, P.L., Barlow, D.H., Duncan, S., Greaves, D.A., Hawthorne, V.M., MorTon, J.J., YounG, G.A.R. \& Young, J. (1974b) The prevalence of hypertension in an unselected population and the frequency of abnormalities of potassium, angiotensin II and aldosterone in hypertensive subjects. Acta clinica belgica, 29, 276.

Finnerty, F.A., Mattie, E.C. \& Finnerty, F.A. (1973). Hypertension in the inner city. I. Analysis of clinic dropouts. Circulation, 47, 73.

Glasgow Blood Pressure Clinic (1972) Journal of the Royal College of Physicians of London, 7, 87.

HART, J.T. (1970) Semi-continuous screening of a whole community for hypertension. Lancet, ii, 223.

Hawthorne, V.M., Gillis, C.R. \& MacLean, D.S. (1972) Monitoring health in Scotland. International Journal of Epidemiology, 1, 369.

Hawthorne, V.M., Greaves, D.A. \& Beevers, D.G. (1974) Blood pressure in a Scottish town. British Medical Journal, 3,600 .
HAWTHORNE, V.M. (1975) Screening for hypertension. Lancet, i, 326.

LANGFIELD, S.B. (1973) Hypertension-deficient care of the medically served. Annals of Internal Medicine, 78, 19.

LEADING ARTICLE (1974) A nurse practitioner. Lancet, i, 608. $\overrightarrow{\overline{\vec{H}}}$

LEw, E.A. (1973) High blood pressure, other risk factors and $\stackrel{\vec{D}}{\rightarrow}$ longevity. The insurance viewpoint. American Journal of $\bar{C}$ Medicine, 55, 281.

Malins, J.M. \& Stuart, J.M. (1971) Diabetic clinic in a general practice. British Medical Journal, 4, 161.

Miall, W.E. \& BrenNAN, P.J. (1976) A pilot trial of treatment for mild hypertension; Interim Report of the Medical Research Council's trial in Britain. Clinical Science and o Molecular Medicine, 48, $165 \mathrm{~S}$.

Moore, M.F., Barber, J.H., Robinson, E.T. \& TAYlor, T.R. (1973) First-contact decisions in general practice. A comparison between a nurse and three general practitioners. Lancet, i, 817.

Padfield, P.L., Nelson, C.S., Beevers, D.G., Hawthorne, V.M., Greaves, D.A., Duncan, S., Blyth, M. \& Young, J. (1975) Hypertension and the renin-angiotensin system in un unselected population. In: Hypertension, its Nature and Treatment (Ed. by D. M. Burley), p. 19. Ciba, Horsham, England.

PearT, W.S. (1973) The organisation of a multi-centre randomized control therapeutic trial for mild to moderate hypertension. Clinical Science and Molecular Medicine, 45, $67 S$.

Prineas, R.J., Stephens, G.B. \& Lovell, R.R.H. (1973) Early consequences of screening for hypertension in a community. Clinical Science and Molecular Medicine, 45, 47S.

Rose, G.A., Holland, W.W. \& Crowley, E.A. (1964) sphygmomanometer for epidemiologists. Lancet, i, 296.

SACKETT, D.L. (1974) Screening for disease: cardiovasculat diseases. Lancet, ii, 1189.

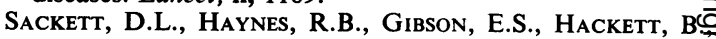
TAYLOR, D.W., ROBERTS, R.S. \& JOHNSTON, A.L. (1975) Randomized clinical trial of strategies for improved medication compliance in primary hypertension. Lancet, i, 1205.

Sinclair, R.G. (1969) Hypertension. A study in general practice. Journal of the Royal College of General Practitioners, 17, 17.

SPITZer, W.O., Sackett, D.L., Sibley, J.C., Roberts, R.S,. Gent, M., Kergin, D.J., Hackett, B.C. \& Olynich, B.C. (1974) The Burlington randomized trial of the nurse practitioner. New England Journal of Medicine, 290, 251.

TAGUCHI, J. \& FreIS, E.D. (1974) Partial reduction of blood pressure and prevention of complications in hypertension. New England Journal of Medicine, 291, 329.

Turner, R.W.D. \& BaLL, K. (1975) Screening for hypertension. Lancet, i, 628.

Veterans Adsinistration Co-operative Study Group on ANTIHYPERTENSIVE AGENTS (1975) Return of elevated blood pressure after withdrawal of antihypertensive drugs. Circulation, 51, 1107.

WILBER, J.A. \& BARROW, J.G. (1972) Hypertension-a community problem. American Journal of Medicine, 52, 653.

WILHELMSEN, L. (1975) The treatment of hypertension in a Swedish community: the problem of borderline hypertension. Acta medica scandinavica, Suppl. 576, 99. 